\title{
DIGITAL RADIOGRAPHY CORROSION MAPPING ON GAS PIPELINES
}

Digital radiography $(D R)$ is a powerful technique that can be used in non-destructive testing for identification of internal or external defects and corrosion mapping. New generation of digital flat panel detectors become more and more competitive to film detectors, however the transition from film to digital radiography is not always the best choice for every NDT organization especially from the point of view of investments. The paper introduces the application of digital corrosive radiography mapping on gas pipelines using a portable flat panel detector. The experimental part is focused on determining the residual thickness of the pipelines in service.

Keywords: Digital radiography, corrosion mapping, gas pipelines, flat panel detector.

\section{Introduction}

During the past two decades, digital radiography has supplanted screen-film radiography in many industrial applications. Today, manufacturers provide a variety of digital imaging solutions based on various detector and readout technologies. Digital detectors allow implementation of a fully digital picture archiving and communication system, in which images are stored digitally and are available anytime. One of them is also portable digital radiography system. Portable digital radiography provides many benefits to users. Fast images upon request for immediate analysis mean there is no compromise on image quality and no repositioning. DR systems enable reduction of working time and costs while enlarging the profits of NDT service providers. This modern DR system can be used not only to identify defects and weld materials but also to corrosion mapping on gas pipelines in services [1].

\section{Digital radiography}

Digital radiography flat-panel systems with integrated readout mechanisms were introduced in the market by the end of the 1990s. Flat-panel systems, also known as large-area X-ray detectors, integrate an X-ray-sensitive layer and an electronic readable system based on thin-film transistor (TFT) arrays. Detectors using a scintillator layer and a light-sensitive TFT photodiode are called indirect-conversion TFT detectors. Those using an X-ray-sensitive photoconductor layer and a TFT charge collector are called directconversion TFT detectors. The reference to amorphous silicon (a-Si), which is used in TFT arrays to record the electronic signal, should not be confused with a-Se, the material used to capture X-ray energy in a direct digital detector. The structure of a DR flat-panel system is shown in Fig. 1.

TFT arrays are typically deposited onto a glass substrate in multiple layers, with readout electronics at the lowest level, and charge collector arrays at higher levels. Depending on the type of detector being manufactured, charge collection electrodes or lightsensing elements are deposited at the top layer of this "electronic sandwich" [2].

The advantages of this design include compact size and immediate access to digital images. The performance of DR systems greatly exceeds the performance of computed radiography (CR) systems, which have conversion efficiencies of $20-35 \%$, and of screen-film systems for industrial radiography, which have nominal conversion efficiencies of $25 \%$ [3].

Wireless DR flat-panel systems have become commercially available by 2009. Wireless DR systems are non-integrated detectors that could be used to obtain radiographs in a similar way to CR. With wireless DR detector it is mandatory to use a wireless LAN for communications between the DR detector unit and the workstation console. This way each performed

\footnotetext{
* ${ }^{1}$ Radoslav Konar, ${ }^{1}$ Milos Mician, ${ }^{2}$ Miroslav Bucha, ${ }^{3}$ Peter Vrzgula, ${ }^{4}$ Ivo Hlavaty

${ }^{1}$ Department of Technological Engineering, Faculty of Mechanical Engineering, University of Zilina, Slovakia

${ }^{2}$ SPP-Distribucia, a.s., Nitra, Slovakia,

${ }^{3}$ SPP-Distribucia, a.s., Zilina, Slovakia

${ }^{4}$ VSB - Technical University of Ostrava, Faculty of Mechanical Engineering, Ostrava - Poruba, Czech Republic

E-mail: radoslav.konar@fstroj.uniza.sk
} 


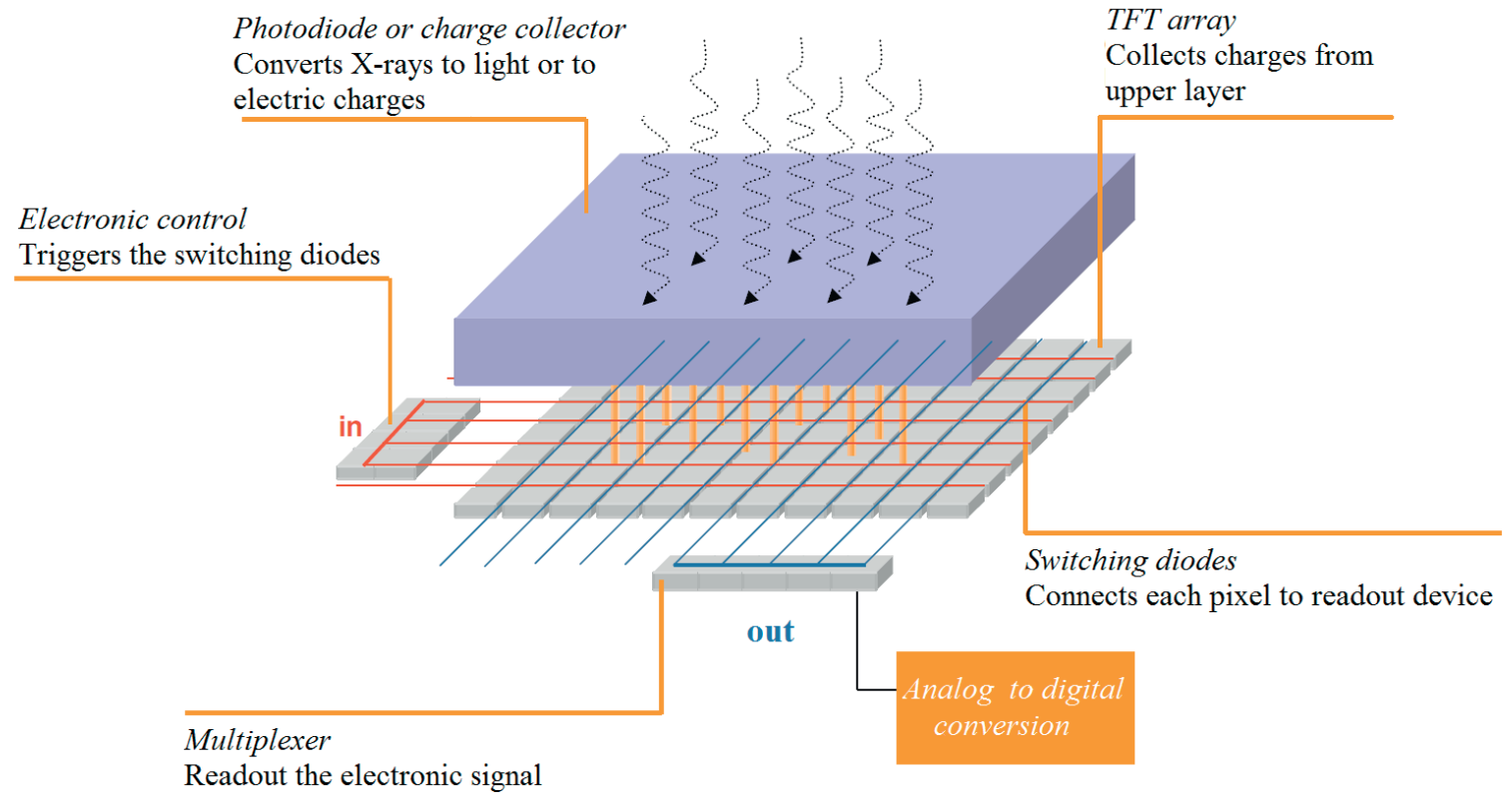

Fig. 1 Flat- panel structure [1]

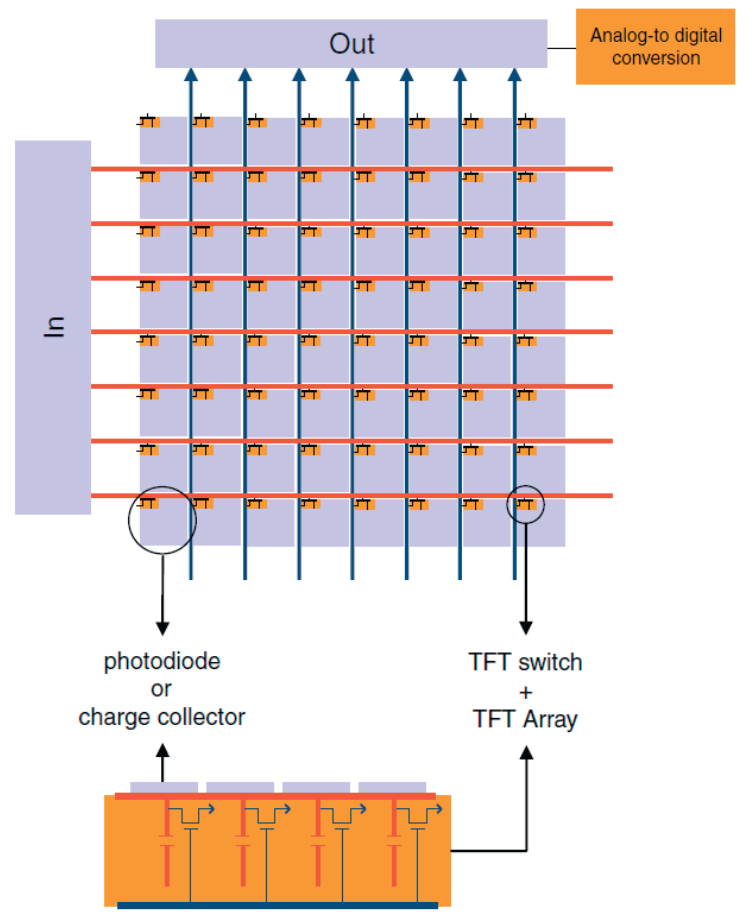

Fig. 2 TFT array [1]

radiograph is transferred at almost real time from the cassette DR to the workstation. The DR cassette includes a built in battery to power supply and this allows the detector's necessary autonomy to obtain several radiographs and to transfer the obtained radiographs to the system for further viewing [4]
DR flat-panel detector use the direct conversion of X-ray radiation to digital format for display of testing results (digital radiograph). Direct conversion systems use a-Se as the semiconductor material because of its X-ray absorption properties and extremely high intrinsic spatial resolution [4 - 5].

Before the flat panel is exposed to X-rays, an electric field is applied across the selenium layer. Then the X-ray exposure generates electrons and holes within the a-Se layer: the absorbed $\mathrm{X}$-ray photons are transformed into electric charges and drawn directly to the charge-collecting electrodes due to the electric field. Those charges proportional to the incident X-ray beam are generated and migrate vertically to both surfaces of the selenium layer, without much lateral diffusion. At the bottom of the a-Se layer, charges are drawn to the TFT charge collector, where they are stored until readout. The charge collected at each storage capacitor is amplified and quantified to a digital code value for the corresponding pixel. During the readout, the charge of the capacitors of every row is conducted by the transistors to the amplifiers (Fig. 2) [6 - 7].

\section{Gas pipeline corrosion mapping by digital radiography}

Experimental part of the article describes digital radiography corrosion mapping a real gas pipeline area with dimension of $185 \times 150 \times 6.2 \mathrm{~mm}$. Material of testing gas pipeline is L360NB.

X-ray tubes with an output power of 25 to $225 \mathrm{kV}$ were used as a radiation source. X-ray tube testing voltage was set to 120 $\mathrm{kV}$ and the exposure time was 8 second. Wireless digital X-ray 

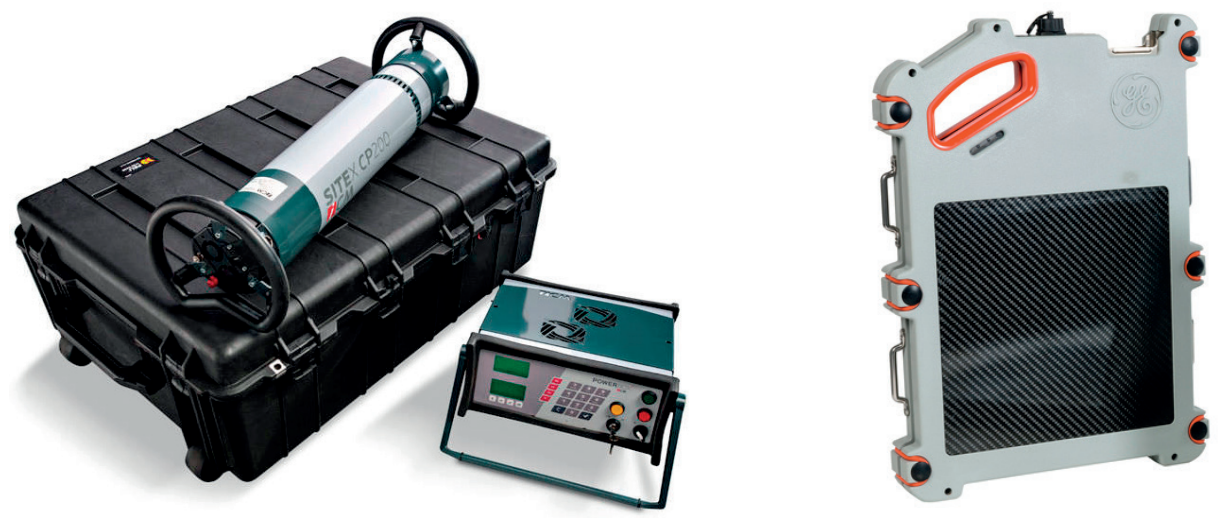

Fig. 3 X-ray tube (left), DDA panel (right)

detector GE DXR250C-W was used for corrosion mapping by digital radiography (Fig. 3) [8].

The digital detector array (DDA) provides a large active area, enabling easy film replacement. The DDA utilizes a CsI (Cesium Iodide) scintillator with optimized noise and resolution parameters to provide premium imaging over a wide range of parts and material types. DDA technical parameters are shown in Table 1.

The experimental sample was tested by radiography from distance of $400 \mathrm{~mm}$ for time 8 second. The result of this testing is a digital radiograph. Radiograph as well as the real sample with measured general corrosion defect dimensions are shown in Fig. 4.

Three corrosion defects are identified in the sample, wherein the one of which has a pipe wall corrosion perforation. Evaluation of real defect dimensions was done in AutoCAD and evaluation of radiograph was done in the program GE Rhythm DICONDE [3 - 9].

Residual thickness evaluation in two selected lines was conducted on defect No. 1. The measurement results were compared to the real thicknesses, which were measured by
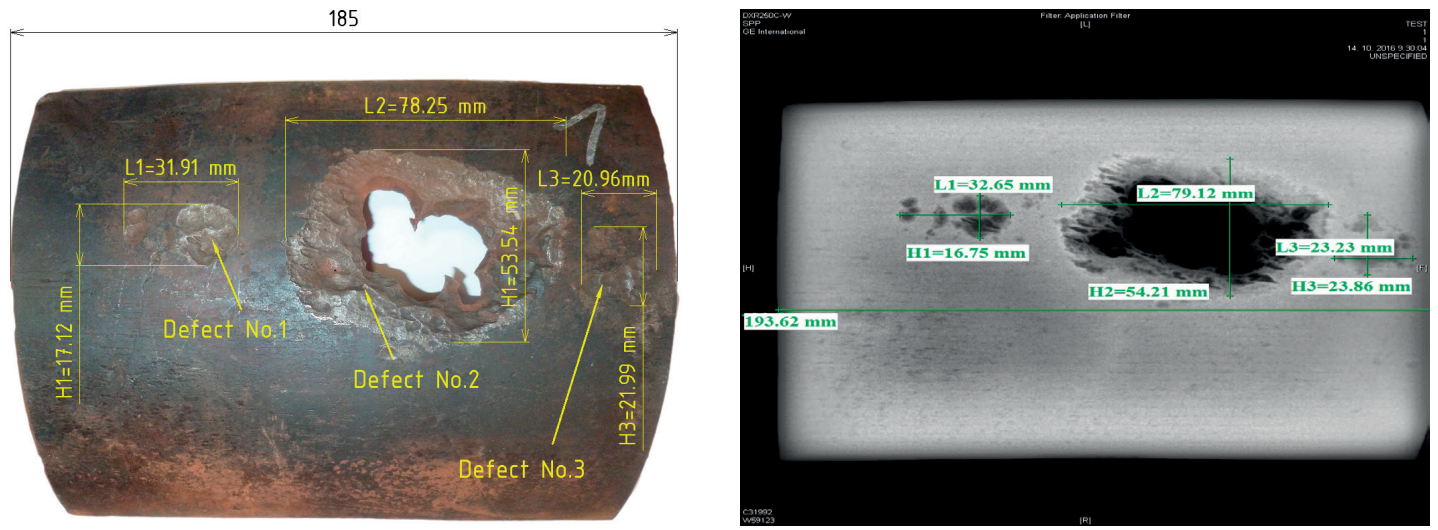

Fig. 4 Real sample (left) and radiograph (right) with general dimensions of defect

DXR 250C-W technical specifications [3]

\begin{tabular}{|c|c|c|c|c|}
\hline FXR 250C-W technical specifications [3] & Table 1 \\
\hline Amorphous silicon & Geintillator Material & Active Area & Image Format & $\begin{array}{c}\text { Operating } \\
\text { Temperature }\end{array}$ \\
\hline Pixel Pitch & A/D Conversion & Exposure Time & Weight & $-20^{\circ} \mathrm{C}$ to $50^{\circ} \mathrm{C}$ \\
\hline $200 \mu \mathrm{m}$ & 14 bits & $130 \mathrm{~ms}-150 \mathrm{~s}$ & $3.5 \mathrm{~kg}$ & $\begin{array}{c}\text { RH, } 10-90 \% \text { non- } \\
\text { condensing }\end{array}$ \\
\hline
\end{tabular}




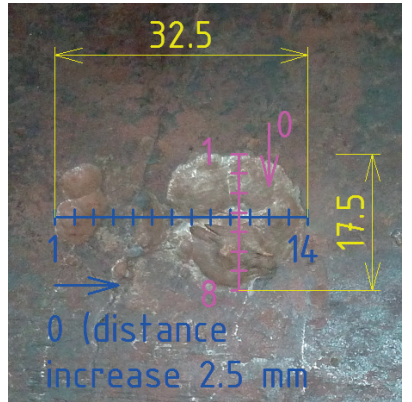

\begin{tabular}{|c|c|c|c|c|c|}
\hline \multirow[b]{2}{*}{ Line 1} & \multicolumn{2}{|c|}{ Residual thickness } & \multirow[b]{2}{*}{ Line 2} & \multicolumn{2}{|c|}{ Residual thickness } \\
\hline & $\begin{array}{l}\text { Mechanical } \\
\text { gauge }[\mathrm{mm}]\end{array}$ & Radiography [mm] & & $\begin{array}{l}\text { Mechanical } \\
\text { gauge }[\mathrm{mm}]\end{array}$ & Radiography [mm] \\
\hline 1 & 6.2 & 6.21 & 1 & 6.2 & 6.19 \\
\hline 2 & 5.3 & 5.38 & 2 & 5.8 & 5.85 \\
\hline 3 & 5.9 & 6.00 & 3 & 5.1 & 5.28 \\
\hline 4 & 6.2 & 6.25 & 4 & 5.5 & 5.61 \\
\hline 5 & 6.0 & 6.17 & 5 & 6.2 & 6.14 \\
\hline 6 & 5.5 & 5.72 & 6 & 4.5 & 4.45 \\
\hline 7 & 6.2 & 6.27 & 7 & 4.8 & 4.92 \\
\hline 8 & 6.1 & 5.99 & 8 & 6.2 & 6.18 \\
\hline 9 & 5.4 & 5.31 & & & \\
\hline 10 & 5.1 & 5.19 & & & \\
\hline 11 & 5.3 & 5.18 & & & \\
\hline 12 & 4.8 & 4.85 & & & \\
\hline 13 & 5.4 & 5.48 & & & \\
\hline 14 & 6.2 & 6.15 & & & \\
\hline
\end{tabular}

- Line 1

- Line 2

mechanical gauge. Residual thickness of experimental sample for defect No. 1 is listed in Table 2.

Results of measurements are in Fig. 5, which shown the graph of residual thickness and its location along the selected line. Residual thickness was measured by mechanical gauge and digital radiography.

Evaluation of the radiograph residual thickness is based on the gray scale, and thus the shade of gray is darker it means that the thickness is less and vice versa. Differences between measured thickness by mechanical gauge and using DR system were minimal. The maximum difference $0.22 \mathrm{~mm}$ was observed in point 6 of the line 1 . This difference is in terms of determining the residual thickness on pipelines acceptable.

\section{Conclusions}

Digital radiography is becoming a powerful tool in the identification of defects and measurements of residual material thicknesses. Its main advantage is the short exposure time and quick evaluation of measurement records.. The differences between the residual thicknesses measured on the real sample
Residual thickness - Line 1

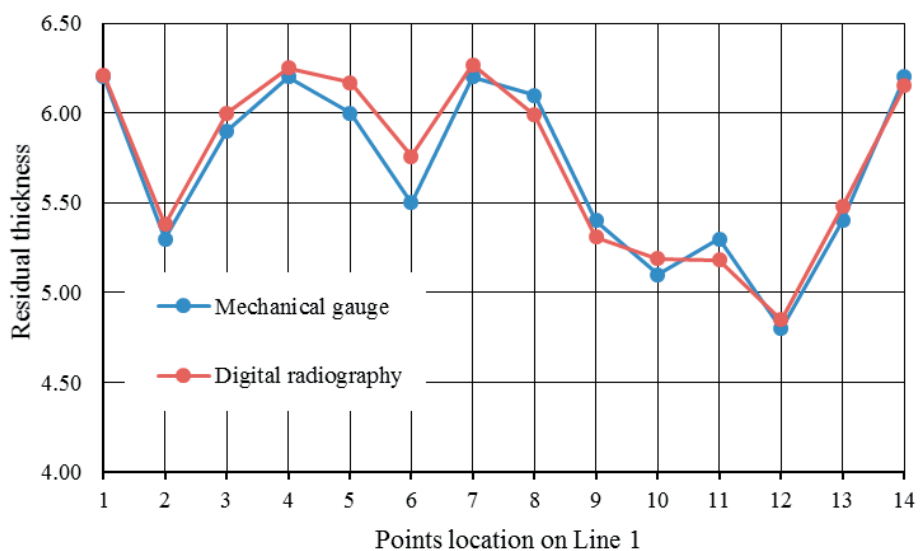

Residual thickness - Line 2

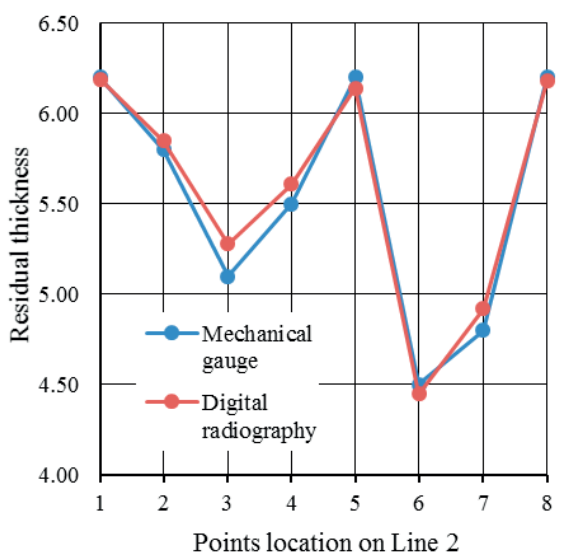

Fig. 5 Residual thickness graph: Line 1 (left), Line 2 (right) 
by ultrasound system and digital radiography are minimal; it indicates the reliability of DR system. The disadvantage of digital radiography is particularly high cost.

\section{Acknowledgement}

This work has been supported by the Scientific Grant Agency of Ministry of Education of the Slovak Republic, grants KEGA 034ŽU-4/2015. Authors acknowledge the grant agency for support.

\section{References}

[1] KORNER, M. et al.: Advances in Digital Radiography: Physical Principles and Systems Overview. RadioGraphics, vol. 27, No. 3, 2007, 675-686.

[2] FABIAN, P., JANKEJECH, P., KYSELOVA, M.: Simulation of Roundness, Hardness and Microstructure of Bearing Rings with thin Cross Sections by using SYSWELD, Communications - Scientific Letters of the University of Zilina, vol. 16., No. 3A, 2014, 124-129.

[3] GENERAL ELECTRIC COMPANY: Inspection Technologies - Wireless Digital Detectors, 2013. Online: https://www.gemeasurement. com/sites/gemc.dev/files/dxr250cw-uw_wireless_detectors_array_brochure_english_0.pdf.

[4] KONAR, R., BUCHA, M., VRZGULA, P.: Using a Non-Destructive Testing in Gas Sector by Computer and Digital Radiography. Slovgas, vol. 15, No. 1, 2017, 24-28.

[5] NOVAK, P., MESKO, J., ZMINDAK, M.: Finite Element Implementation of Multi-pass Fillet Weld with Phase Changes Phased Array. Manufacturing Technology, vol. 13, No. 1, 2013, 79-85.

[6] BRONCEK, J., JANKEJECH, P., FABIAN, P., RADEK, N.: Influence of Mechanical Anisotropy in Low Carbon Microalloyed Steel. Communications - Scientific Letters of the University of Zilina, vol. 17, No. 3, 2015, 25-30.

[7] LAGO, J., BOKUVKA, O., NOVY, F.: The Weld Toe Improvement of Advanced HSLA Steel by Laser Remelting. Materials Today, vol. 3, No. 4, 2016, 1037-1040.

[8] BRUNA, M., BOlibrUCHOVA, D., PROCHAZKA, P.: Numerical Simulation of Melt Filtration Process. Communications Scientific Letters of the University of Zilina, vol. 18, No. 1A, 2016, 70-74.

[9] ROZOWICZ, S., TOFIL, S., ZRAK, A.: An Analysis of the Microstructure, Acrostructure and Microhardness of NiCr-Ir Joints Produced by Laser Welding with and without Preheat. Archives of Metallurgy and Materials, vol. 61, No. 2b, 2016, 1157-1162. 